\title{
Importance of School Social Work in War and Conflicts Zone
}

\author{
Prof. Dr. Nurdan Duman
}

Yaser SNOUBAR

\begin{abstract}
Ongoing wars and conflicts in many countries in the world resulted in various problems effecting Men and societies, especially children. This situation requires serious professional interventions, especially in dealing with children affected by political violence. At the same time they are the most important group in social work interventions which aimed to protect, prevent and treat them. School is actually the best source to reach the children and their parents in such crises, as well it is a best source because it is where social work can help children and provide them with supporting services. Direct and indirect exposure to violence affects their behavior and growth requiring direct work with the child and his family. Undoubtedly that social work intervention with children in times of war and conflict requires sufficient skills and information about the difficulties they suffer. This article discusses the impact of living in an environment of war and conflict on children and the importance of school social work intervention.
\end{abstract}

Keywords: School social work, war and conflict, political violence, children victims of conflicts

\section{Impact of violence caused by war and conflict on children at school}

Living in an environment of war and conflict causes children to lose their rights as well involves the emergence of behavioral problems affecting their physical, moral, social and psychological development. Consequently and negatively this affects the participation of children within the school environment.

A symptom of post-traumatic stress disorder often appears in children who have been exposed to or witnessed violence. These negative effects establish peer relationships and peer school performance. Besides the impact of violence on children, there are other things created by an environment of war and conflicts that have a direct impact on the mental health of children for instance poverty, malnutrition, family relations and violence emergin from environment.

Generally children still under the influence of the conflicts they see in public, television and environment can apply the pattern of violent behavior against each other in school. Exposing or witnessing the violence affects the children's concentration and participation in class and in other activities in school (Snoubar, 2010; Snoubar \& Duman, 2015).

Psychological hazards to children includes, terrible events observation and threats against loved ones, show the terrible events in the media, torture, threats and self-blame. Moreover, children from an early age can be danger-measured by reading concerns of their parents. This phenomenon is called social referencing (Masten et al. 1990; Masten and Narayan, 2012). Therefore it is necessary to include the presence of parents in any intervention made to the children.

\section{School Social Work in Conflict Community}

School is one of the most important places where could be managed the case in dealing with children in the times of crisis. Accessing to children in times of distress through the school and providing them with psychological and social support is a crucial step in the field of child protection in a risked environment. In fact, school facilitates the work of social workers in determining the risk factors and problems suffered by children and affecting their development and school performance.

Activities that can be done inside the school include large numbers of students and split them to individuals, groups and society. At the same time work can be done with teachers and all school staff in order to support and assist children within the activities, programs or seminars. 
In a conducted research to determine the psychological reactions of children to war and conflicting events, findings from the national study of school-based screening in Palestine study the psychological reactions of Palestinian children to Israeli occupation showing that extensive exposure to violence was associated with higher levels of post-traumatic distress and more somatic complaints in Palestinian children. Students reported symptoms meeting the criteria for PTSD and more girls than boys reported somatic complaints. Thus, school-based screening can be a very important method for case identification of student's psychological problems as a result of living in a conflict environment (Abdeen et al, 2008). Therefore school social work practice and interventions play a central role in the contribution to solving the problems for children affected by political violence.

\section{Direct work with children victims of conflicts}

Providing a safe space where can be work with children individually or within a group is the first step to be taken in the school social work intervention to protect children in times of distress and address their needs. It is possible to evaluate schools as the most appropriate place to reach children who are living in conflict and war to provide them with the needed support. Social work intervention in the school environment includes working with individuals and groups, as well psychosocial support programs and activities for all affected students. But the application of psychological and social support programs and work with children in times of distress and crisis require the social workers to have special skills.

Richman (1993) Suggests that the social worker or psychologist working with children in distress and conflict environment must have various necessary skills to deal with children in such crises such as communicate skills with children of different ages such like listening, use of easy language understood by the concerned child, use of body language, establishment of a relationship of trust and concern for his/her feelings, observing him/her, knowing or more like understanding when the subject needs help providing the latter with support and consultancy services, understanding what he/she knows about death and talking to them about it, having the ability to deal with children who become handicapped from the conflicts and last but not least communicate the child's family.

In the school environment, social worker uses special knowledge in overcoming learning difficulties and behavior problems of children at school and uses it to helps the school staff and parents to mobilize together for examining the causes of these inconvenient and to find solutions to them. The work of a social worker supports the teacher's work which is why usually social workers at school becomes in close collaboration with teachers. Social worker helps young students in finding solutions to their problems such as teacher-student relations, peer relations and conflicts, student's success at school, aggressive behavior and school absenteeism. Social work practice in schools requires the use of extensive knowledge and skills in the various forms of behavior. He must understand the different norms and behaviors that occur in the physical and emotional development of the child himself. At the same time the latter needs to, have adequate knowledge about issues such as being continuously interacted with the child-teen and colleagues, evaluate the problematic behavior observation, participate in the decision-making process at school, promoting mental health practices that will contribute to early diagnosis and treatment of pathological cases and use social resources according to the needs and problems (Duman, 2000). Recreation and structured activities in the school environment has helped many children in the normalization of their behavior after exposure to violence. Secure game schedules provide a mechanism to monitor their child protection concerns in difficult and hazardous environments. It should be a priority to integrate psychosocial services to schools in times of chaos and encourage family as well as community involvement to reach the children in need (Boothby \&Melvin, 2009). Here, appears the role and skills of social workers in working at the community level.

Strategies in order to establish psychosocial support for children in war and conflict situations must beef up appropriate traditional protection and support mechanisms besides drawing on local norms, values, and worldviews. Community participation and mobilization strategies should be at the core of children response to psychosocial needs and support (Duncan \& Laura, 2004). Children demonstrate different reactions to the crisis; the loss of a family member, especially the parents is one of the hardest situations that can be faced by a child. The latter in such a case feels verily lonely believing that no one can understand his/her experiences. With the traumatic loss crisis, children have two different kinds of cognitive and emotional experiences and they are: trauma and grief responses (Gaffney, 2006: 1006). In this situation a social worker has to be able to identify a crisis response and deal with it by both adopting a structured approach and then appropriately timing the handing back of control to the individual. Crisis intervention is short-term and intensive; supportive and cognitive behavioral approaches can help to reduce panic symptoms (Higha, 2006: 193). 
A social worker has an important role in working to protect and defend children's rights at the international level and act as a mediator. However this one has to communicate with local and international organizations in order to put an end to the violations of their rights and create a safe environment that would offer a psychological and social support programs by working with individual and groups.

\section{Psychological and social promotion of children at the school in the conflict environment}

It can provide psychological and social support programs for children affected by wars and conflicts on the basis of the school social work through professional cooperation and the development of programs and models to provide these services.

"Strengthening the role of schools as multifunctional centers. Some development programs focus on the returning back to normalize and stabilitize the living conditions. Other programmes are more specialized, helping groups of children deal with specific situations through various methods which often include creative means such as drawing and playing. Such programs aim to strengthen children's social environment, helping teachers and parents to support their children and thus focus on increasing the level of knowledge. It is intended for future development programs such as the psycho-social wellbeing of children" (Snoubar \& Duman, 2015).

Toros (2013) developed The Model of the Psychosocial Support and Crisis Intervention (PSCI) Program as a school-based intervention in conflict and war zone. The PSCl program consisted of five phases: firstly training a team of specialists to work with children in war and conflict environment, secondly training school teachers and seminar for managers, thirdly Development of a network for case management and referral system for critical cases, fourthly supervision and advanced training of master trainers and school support persons, finally Providing treatment for psychological trauma for children and their families through a mobile team of psychologists and social workers.

As reported in model the success of the school social work intervention is based on several dimensions. These dimensions lie in the preparation and training of specialists and involve family and staff within the school community and outside to provide psychosocial support for children victims of armed conflict. This requires skills and sufficient information in the school social worker or case manager.

\section{Conclusion}

Reaching children who are victims of armed conflict and to provide psychosocial support is an important issue. Success of this issue is linked to training the largest number of specialists dealing with these cases, in addition to working as a team in order to manage a social case. The school is the main axis of access to young victims of war and conflict. Countries suffering from permanent conflicts often lack centers that can accommodate all children and provide them with psychological and social support. Therefore, schools are the most appropriate places to provide these services in the areas of conflict. Social work has a great and very important role in working with victims that are children, through case management and work with them as individuals and groups, in addition to working at the community level. School social work with its holistic approach working to solve the problems of children in the school and provide psychological and social support programs through professionals having information and skills to work with children in times of distress and crises. Thus this promotion of the importance of school social work in working with children in conflict environment can be recommended to activate the role of school social work in war and conflict zones, especially in permanent conflict zones as in the Israeli-Palestinian conflict. In addition to providing psychosocial support programs for social workers dealing with children in conflict and pressure environment, it should be noted recommendation to develop and implement special training programs by the International Association of Social Workers targeted social workers who are working in the field of school with children who are victims of war and armed conflicts.

\section{References}

[1] Abdeen, Z., Qasrawi, R., Nabil, S., Shaheen, M. (2008). Psychological reactions to Israeli occupation: Findings from the national study of school-based screening in Palestine, International Journal of Behavioral Development, 32(4), 290-297. 
[2] Boothby, N., \& Melvin, C. H. (2009). Towards best practice in school-based psychosocial programming: A survey of current approaches. In R. Mollica (Ed. ), Refugee mental health. Nashville, TN: Vanderbilt University Press.

[3] Duman, N. (2000), Ankara Liselerinde Çeteye Katılma Potansiyeli Olan Öğrenci Grupları ve Okul Sosyal Hizmeti, Ankara.

[4] Duncan, J., and Laura, A. (2004). Children in Crisis: Good Practices in Evaluating Psychosocial Programming. London: Save the Children Federation.

[5] Gaffney, D (2006). The Aftermath of Disaster: Children in Crisis. JOURNAL OF CLINICAL PSYCHOLOGY: IN SESSION, Vol. 62(8), 1001-1016.

[6] Higham, P. (2006) Social Work: Introducing Professional Practice, London, Sage.

[7] Masten, A. S., \& Narayan, A. J. (2012). Child development in the context of disaster, war and terrorism: Pathways of risk and resilience. Annual Review of Psychology, 63, 227-257. doi: 10. 1146/annurev-psych120710-100356, http://www. annualreviews. org/eprint/XBCcryg7FzG8kmDbTxeM/full/10. 1146/annurevpsych-120710-100356.

[8] Richman, N. (1993). Communicating with Children: Helping Children in Distress. Save The Children Development Manuals.

[9] Snoubar, Y. (2010). Savaş ortamlarında bulunan çocukların sorunları ile sosyal hizmet (örnek olarak Filistin). Sosyal Hizmet, Sosyal Hizmet Uzmanları Derneği Yayını, sayı 20, $13-17$.

[10] Snoubar, Yaser \& Duman, Nurdan (2015) Using Social Holistic Approach in Working with Children who are in the War Zone. Mediterranean Journal of Social Sciences MCSER Publishing, Rome-Italy, 231-237.

[11] Toros, K. (2013). School-Based Intervention in the Context of Armed Conflict: Strengthening Teacher Capacity to Facilitate Psychosocial Support and Well Being of Children. International Journal of Humanities and Social Science, 3(7) 228-237. 